\title{
Techniques for computer-assisted mapping of rangeland change
}

\author{
STEPHEN R. YOOL, MARY JANE MAKAIO, AND JOSEPH M. WATTS
}

\begin{abstract}
Authors are assistant professor, Department of Geography and Regional Development, University of Arizona, Tucson, Ariz. 85721; research assistant, Department of Geography and Regional Development, University of Arizona, Tucson, Ariz. 85721; and research scientist, U.S. Army Topographic Engineering Center, Alexandria, Virg., 22315-3864.
\end{abstract}

Abstract

Management of grasslands subject to replacement by woody species requires an understanding of the scales and patterns of change and how to detect and express them. We used the Jornada del Muerto Basin of southern New Mexico as a case study, testing the suitability of Landsat Multi-Spectral Scanner (MSS) data for detecting vegetation changes. Cycles of drought and heavy grazing have apparently changed the once extensive grasslands of the upland Jornada and surrounding areas gradually into a patchwork of shrublands and relict grasslands. Integrated remote sensing and geographic information system (GIS) techniques can facilitate automated detection of these rangeland changes. A GIS was used to store and process two 4 band, co-registered multi-temporal Landsat MSS scenes collected in July 1983 and August 1992. Scene-to-scene radiometric calibration was performed using a regression technique. The data were then evaluated for changes 3 different ways using algorithms based on 1) differences between the 'red' (chlorophyll absorption) bands for the 2 scenes; 2) the Euclidean distances between the 'red' and 'near-infrared' bands for the 2 scenes; and 3) a standardized principal components analysis using all 8 MSS bands. A threshold of 3 standard deviations above the mean was applied to each of the 3 resulting 'change' images to represent areas of extreme change. Correlations among these images ranged between 0.83 and 0.95 . We conclude these techniques can identify successfully the patterns and extent of extreme change, and thus have potential value for management of our rangelands resources.

Key Words: remote sensing, GIS, change detection, range management

Arid rangelands cover nearly $50 \%$ of earth's terrestrial surface (Williams et al. 1968). Before the turn of the century, perennial grasslands ranged across the northern Chihuahuan Desert (Buffington and Herbel 1965). Human and natural forces have transformed these once seamless rangelands into shrublands (Gibbens and Beck 1988, Grover and Musick 1990, Schlesinger

Research was funded in part by the U.S. Army Corps of Engineers, Battelle contract number 94028.

All correspondence regarding this research should be addressed to the senior author.

Manuscript accepted 9 June 1996 et al. 1990) that extend from southeastern Arizona (Bahre 1991) to western and southern Texas (Archer et al. 1988, Ritchie et al. 1992). Ungulate grazing has been cited as responsible, in part, for this change, and for resulting ecosystem instability (West 1993).

Remote sensing techniques have assisted mapping and monitoring rangeland change (Warren and Hutchinson 1984, Smith et al. 1990, Franklin and Turner 1992). Changes observed in remotely-sensed data can complement ecological assessments of restorable rangelands. Both restoration and long-term management efforts require location and monitoring of the spatial patterns of change. Regional maps of rangeland vegetation change provide range managers with information for setting long-term grazing practices.

We demonstrate in this paper how integrated observations from the Landsat Multi-Spectral Scanner (MSS), and change-detection techniques, can be combined within a GIS to map apparent changes produced by climatic and human forces (e.g., drought, grazing, urbanization) in the Jornada Basin. The Basin is located in the southwestern corner of New Mexico at the northern limit of the Chihuahuan Desert. Arid lands such as the Jornada appear particularly subject to change due to narrow-range climate regimes and lack of soil nutrient reserves (Mabbutt 1984). Field studies by Jornada ecologists offer explanations why change has occurred in this former grassland ecosystem, but these changes have been observed at relatively fine scales (i.e., the individual plant or community) and have not been extended to broader scales (i.e., the Basin). Our focus is on extreme change at regional scales. Any detected change greater than 3 standard deviations above the mean is considered extreme, representing, for example, a change of grassland to barren.

\section{Background and Study Area}

The Jornada Basin lies in south central New Mexico (Fig. 1). Once-abundant Jornada grasslands attracted early pioneer cattle ranchers to the Basin. Only 150 years ago, uplands of the Jornada Basin were dominated by black grama (Bouteloua eriopada). Before the advent of drilling technology in the 1880 's, ranchers limited livestock to populations that could be supported by the natural springs in the bordering mountains. Around the 1880 's, wells were able to tap groundwater reserves. Technology brought water to the surface, which increased livestock numbers and opened the land up to heavy grazing. 


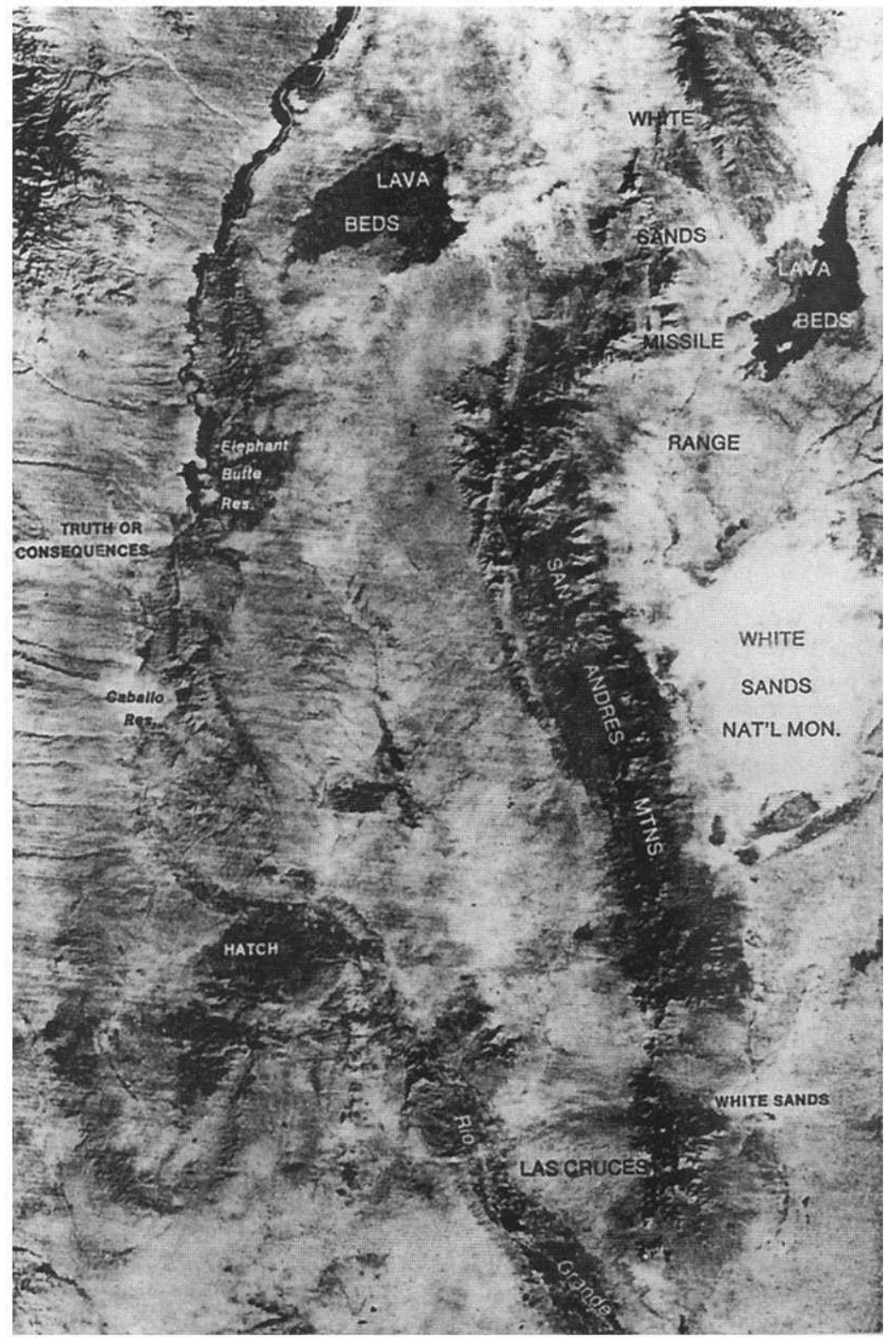

Fig. 1. Location map of the study area. This map shows the Jornada Basin, west of the San Andres Mountains, trending southeastward towards Las Cruces. The right-most of the 2 lava beds (with the panhandle) is the Valley of Fires lava flow. Elephant Butte Resvoir can be seen along the left edge of this map. (Source: Photo Geographic International).

The ecological mechanisms behind the species changes remain controversial (Hennessey et al. 1983, Schlesinger et al. 1990). Episodic drought and heavy grazing have apparently promoted the conversion of grass into shrublands (Schlesinger et al., 1990, West 1993). The fragmented pattern of change detected in the southern Jornada Basin imagery supports, at the comparatively broad scale of Landsat MSS, the patchy spatial patterns seen by ecologists looking at relatively finer scales. Specifically, Schlesinger et al. are sufficient to be detected. Although digital manipulation of remotely sensed data can yield more accurate change detection than visual inspection of the images, there are cautions, particularly in the early stages of image acquisition and processing. The main factors that complicate detection of bona fide vegetation changes using multi-temporal, multi-spectral data sets obtained with the same sensor system are: 1) image registration; and 2) time-dependent differences in radiometric responses.

\section{Selection and Registration of Multi- temporal Data Sets}

One of the basic requirements for vegetation change detection is the availability of at least 2 'anniversary' images of the same land area, to avoid confusion with phenological cycles. In this study, the 2 Landsat MSS data sets were acquired within 3 weeks of the same date: 14 July 1983 and 7 August 1992. These dates occur during the summer monsoon season, which produces locally heavy, spatially-variable rainfall.

Image rectification and registration were performed using the Arc/INFO GIS software. A network of ground control points was selected throughout both data sets. A nearest-neighbor re-sampling approach, which preserves recorded radiances, was used because it is important in change detection studies to compare original values (Jensen 1996).

Registration error of approximately 1 pixel is typically tolerance for change detection studies (Eastman and McKendry 1991). After our registration was complete, scene-wide comparisons between datasets produced a root-mean-square registration error of 1.16 MSS pixels (i.e., $92 \mathrm{~m}$ ). Given the homogeneity common to this and other arid landscapes, an average error just above 1 pixel was considered sufficient to represent significant trends in the spatial patterns of vegetation change. individual plants, formation of 'islands of fertility' by shrubs recruiting nutrients from nearby soils. Resulting nutrient-poor soils were subsequently eroded, or ceased to support perennials.

\section{Materials and Methods}

For this work, we make 2 basic assumptions: 1) Vegetation change modifies spectral responses; and 2) Vegetation changes

\section{Radiometric Correction of Multi-Sensor Data}

We performed radiometric correction of the 1983 and 1992 Landsat data sets to adjust for different sensor gains and offsets between Landsats 4 and 5, and to standardize the datasets for differing sun angle and atmospheric effects. Correction of atmospheric effects is important in change detection studies, because detection of land cover can be affected adversely when uncorrected 
images from different years are compared. We evaluated 4 correction methods: 1) Dark Body Subtraction; 2) Empirical Line Adjustment; 3) Image Regression; and 4) Radiative transfer modeling.

Dark-body subtraction requires pixels of known zero-ground radiance, while the empirical-line technique regresses known ground reflectance to pixel-reflectance values (Chavez 1975, Marsh and Lyon 1980). Though the empirical line technique is reliable, ground reflectance data were unavailable for this study. Radiative transfer models involve a complex mixture of data and assumptions (Chavez 1975) and we consider these models less accurate compared with image-based methods.

After review, image regression was selected. Image regression normalizes one data set to another, using a standard linear regression algorithm to relate the values of pixels at corresponding locations between 2 image dates. We considered the 1992
Landsat 5 data the independent variable, and the 1983 Landsat 4 data, the dependent variable. The 1992 data were the favored independent variable due to the currency and assumed greater radiometric fidelity of Landsat 5 compared with Landsat 4 . The logic used here is the dependent variable can be considered an adjusted image of the independent variable (Eastman and McKendry 1991). Thus the difference between the 2 is one of offset and gain. Image regression standardizes this offset and gain, and further processing using change detection methods may then be used to discern actual changes in vegetation.

\section{Validation of Change using Spatial Correlation}

Given the main objective of this work was identification of extreme vegetation changes, we used different change-detection algorithms to cross-validate detected extremes. Specifically, 3 mutually-exclusive change-detection methods (Euclidean distance, Red-Band 'Differencing' and Standardized Principal Components (SPCA)) were cross-correlated to confirm locations of detected changes. Visual inspection and computer analysis of the cross-correlated images produced significant agreement. Use of spatial correlation not only validates detected change; knowing the precise coordinates of altered areas also makes subsequent ground surveys cost-effective.

\section{Landsat Data and Change Detection Methods}

The Landsat MSS images have a nominal spatial resolution of $79 \mathrm{~m}$ (Price 1987). After geometric and radiometric standardization, a $2209 \times 1726$ pixel rectangle was extracted from the July 1983 (Fig. 2) and August 1992 (Fig. 3) data sets.

Since the launch of the first Landsat, in

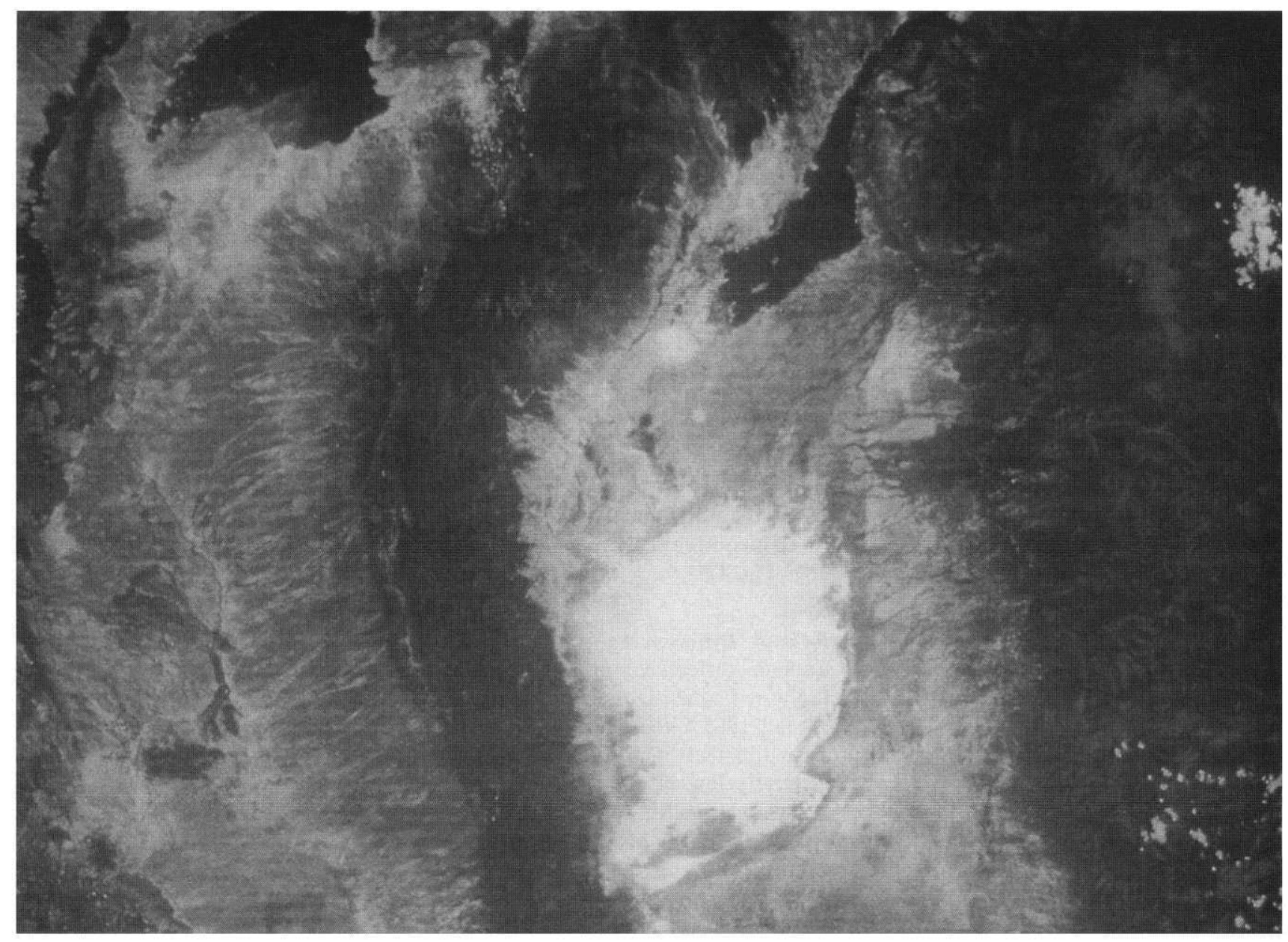

Fig. 2. Gray-scale representation of July 1983 Landsat MSS false-color composite image. 


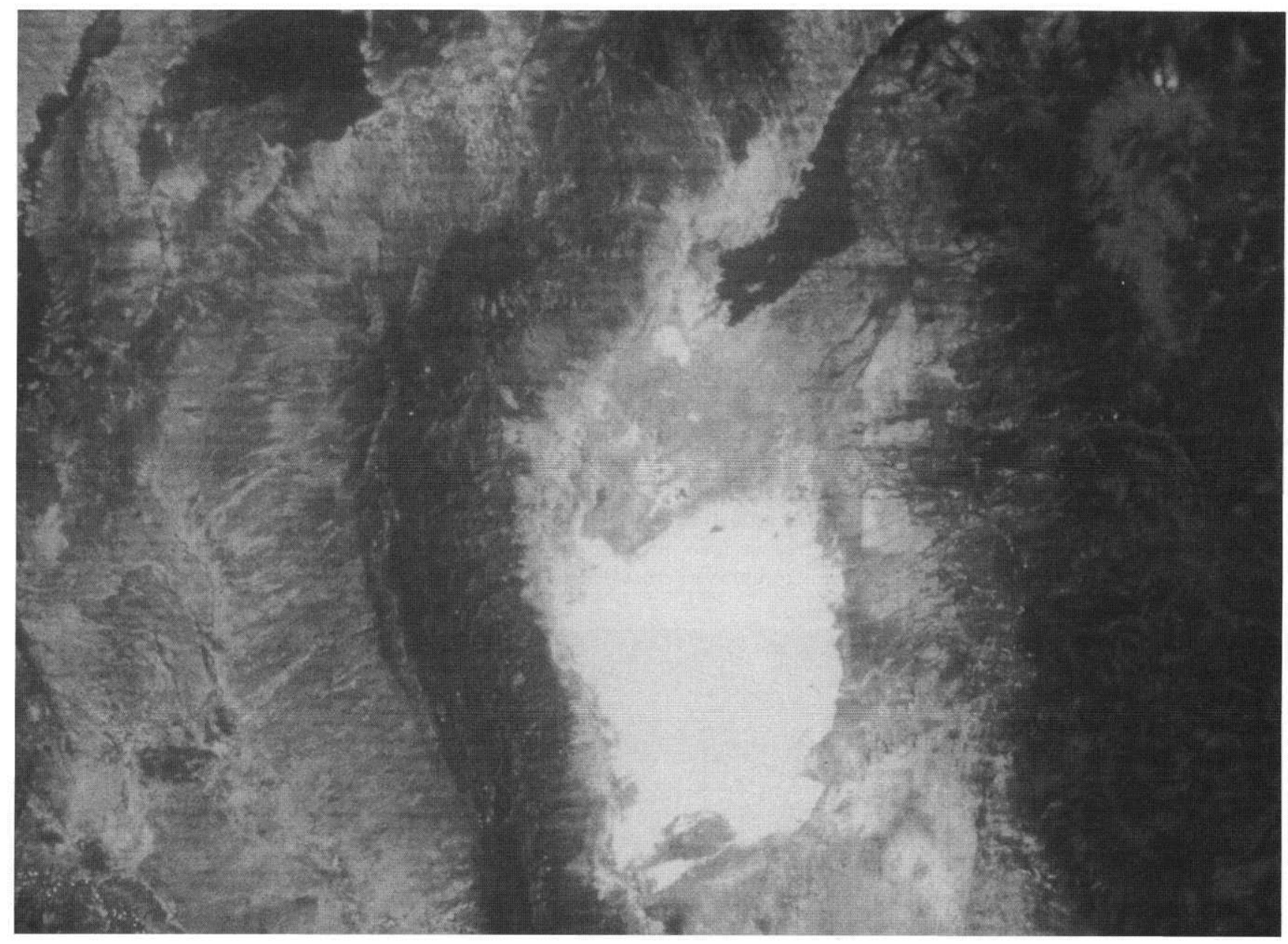

Fig. 3. Gray-scale representation of August 1992 Landsat MSS false-color composite image.

1972, the most common method of detecting land cover change has been visual interpretation of multi-temporal MSS images. Visual interpretation is still widely used and is a direct, fast, manual change detection strategy. The computer-assisted techniques described next provide the opportunity to automate change detection over large areas.

\section{Euclidean Distance}

Vegetation leaf pigments typically absorb red light, while the cell structures reflect near-infrared (NIR) light. If these pigment and structural properties change with time, the amount of this change can be expressed as the Euclidean distances in the red and near-infrared brightness values before and after the changes:

$\mathrm{D}=\mathrm{SQRT}\left[\left(\mathrm{NIR}_{2}-\mathrm{NIR}_{1}\right)^{2}+\left(\operatorname{Red}_{2}-\operatorname{Red}_{1}\right)^{2}\right]$

where $\mathrm{D}=$ Euclidean Distance, and the subscripts refer to time 1 (1983) and time 2 (1992).

Computed Euclidean distances can be used to produce an image depicting change (Fig. 4).

\section{Red-Band 'Differencing'}

A simple 'difference' image was created from the red band digital counts from the 1992 and 1983 Landsat MSS scenes. In arid environments where vegetation cover is generally low, the red band typically provides best results for mapping green leaf cover (Ringrose and Matheson 1991). Both soils and vegetation usually have high reflectances in the near-infrared spectral bands. As a result, reflectance differences in the near-infrared are typically small for soils and vegetation (Franklin et al. 1993, Chavez and MacKinnon 1994). In arid environments a 'difference' image between the red bands from 2 image dates (Fig. 5) may, therefore, detect vegetation change more effectively than can the nearinfrared band difference or vegetation indexes such as the Normalized Difference Vegetation Index (NDVI).

\section{Standardized Principal Components Analysis (SPCA)}

Principal components analysis (PCA) has been used typically for data compression (Jensen 1996), but also has been suggested for change detection (Fung and LeDrew 1987). Unstandardized PCA uses the variance/co-variance matrix to compute the eigenvalues and eigenvectors. In contrast, Standardized Principal Components Analysis (SPCA) uses the correlation matrix, which standardizes the principal components to zero mean and 
equal (unit) variance. This standardization produces even loadings on all of the spectral bands, which is considered important for the resolution of change (Fung and LeDrew 1987).

Using SPCA, all 8 bands from the 2 MSS scenes were merged to create 8 Standardized Principal Component (SPC) images (i.e., SPC1, SPC2, etc. representing the standardized principal component 1 image, the standardized principal component 2 image, etc.). We follow the suggestion of Eastman (1992) who found that SPC1 represents the status quo. Because SPC1 and SPC2 are uncorrelated, SPC2 represents change information.

Table 1. Correlation matrix of change-detection images produced using Standardized Principal Component 2 (SPC2), red-band 'difference' and Euclidean distance change-detection methods. Correlations where produced using the entire $2209 \times 1726$-pixel image (i.e., $n=3,821,734$ )

\begin{tabular}{lccc}
\hline \hline & $\begin{array}{c}\text { SPC2 } \\
\text { Diff. }\end{array}$ & $\begin{array}{c}\text { Red-Band } \\
\text { Dist. }\end{array}$ & Euclid \\
\hline SPC2 & 1 & & \\
Red-Band Diff. & 0.828 & 1 & 1 \\
Euclid. Dist. & 0.824 & 0.948 & 1 \\
\hline
\end{tabular}

\section{Results and Discussion}

Correlation analysis among the techniques produced significant relationships (Table 1). Correlation of the 'change' images showed direct relationships between the Euclidean distance and SPC2 images (0.824), the red-band 'difference' and SPC2 images $(0.828)$, and the Euclidean distance and red-band 'differ- ence' images (0.948). Consequently, all 3 methods produced similar image outputs, though each used a different pathway to discriminate changed areas. The red-band 'difference' method is the simplest computationally and, based on this criterion, appears most favored among change detection methods we tested.

To produce 'change' strata, all images were divided into 6 levels according to

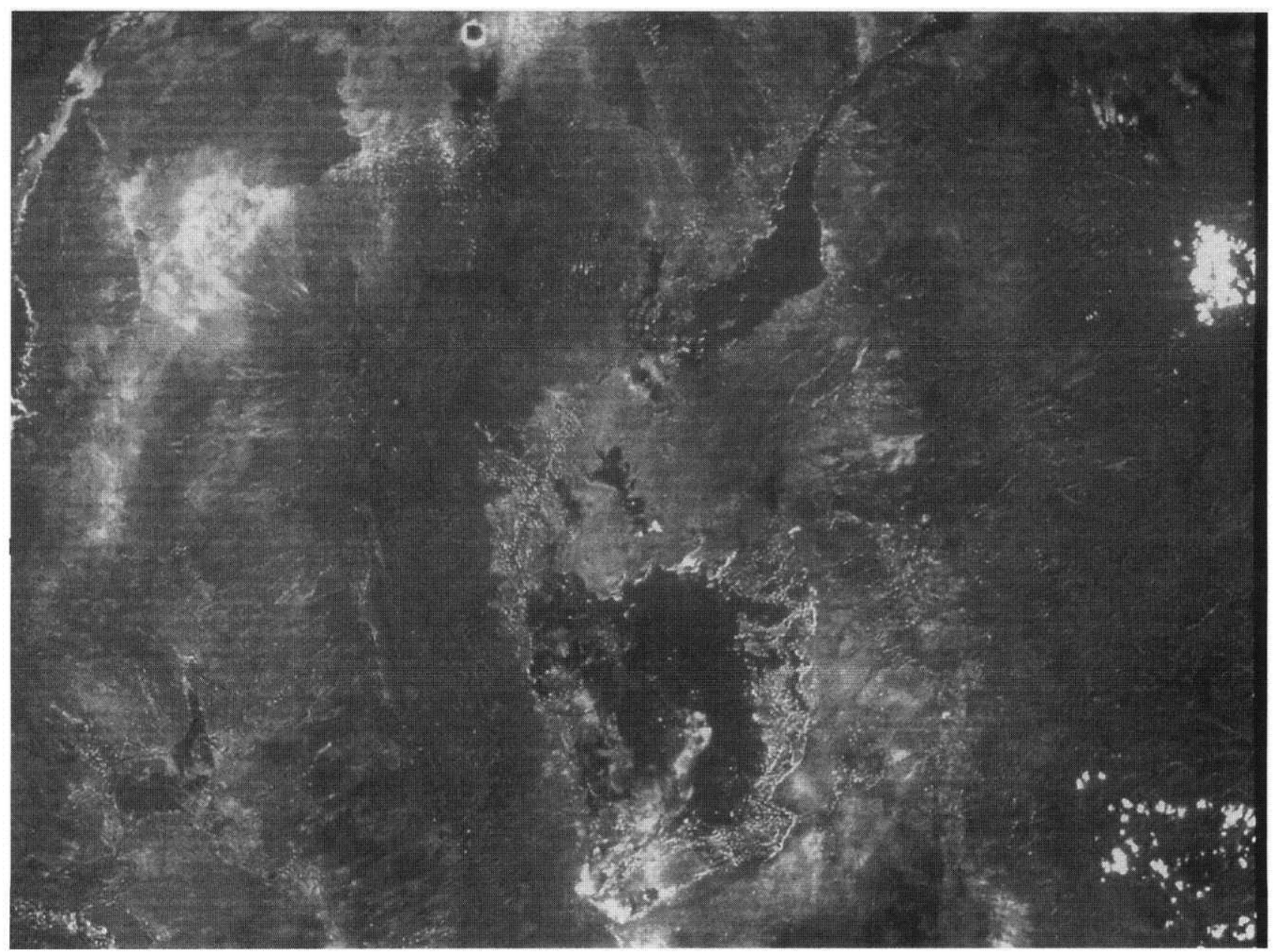

Fig. 4. Euclidean distance 'change' image using MSS2 (Red, 0.6-0.7 $\mu \mathrm{m}$ ) and MSS4 (Near-Infrared, 0.8-1.1 $\mu \mathrm{m})$. Whitest areas indicate greatest change, showing where vegetation cover is sparser on the 1992 than the 1983 images. 


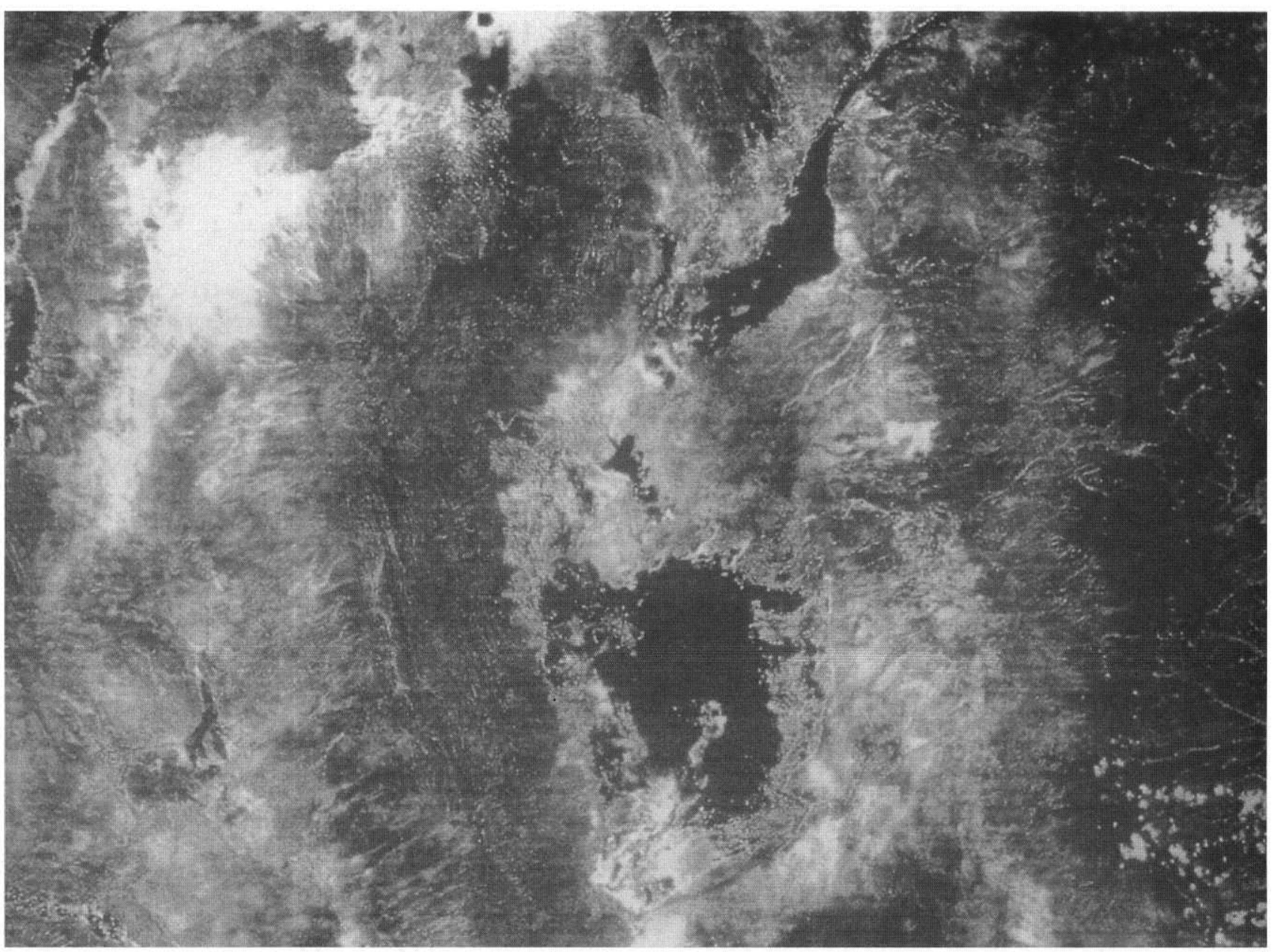

Fig. 5. 'Differenced' Red Bands, 1983 vs. 1992. Whitest areas indicate greatest change. Note the lava beds are dark, indicating little or no vegetation change. We found the dynamic range produced using 'differenced' red bands was greater than produced from 'differenced' NDVI images.

their standard deviations, 3 standard deviations above and below their means. Binary images of 'extreme' change were produced by 'thresholding' them to display only changes greater than 3 standard deviations above their means (Fig. 6 and 7). In these images, areas of extreme change are white. Note the spatial correspondence of the white places in both images.

Areas of known stability and change were used to check the reliability of detected changes. Two areas of apparent stability are the White Sands National Monument and the lava beds. These areas are dark on the Figures 6 and 7, suggesting little or no change. We noted during scene-to-scene registration a change in water levels of Elephant Butte Reservoir (upper left corner on the images) on the July 1983 data set (lower level) and August 1992 data set (higher level). This known change can be seen in the images as the white-outlined shoreline of the reservoir. Finally, the spatial patterns of change seen along the Rio Grande River, in the southwest corner of the images, are associated with known changes in crop rotation.

Consistent spatial patterns of change are evident in all processed images, where all white areas indicate less vegetation in the 1992 scene than in 1983 scene. One region showing change extends as a large swath south of the large lava flow, east of Elephant Butte Reservoir. Continuing south in the Basin towards Las Cruces, the pattern of decreased vegetation appears more fragmented.

The 'islands of fertility' hypothesis attributed to Schlesinger et al. (1990) was posed at the scale of the individual plant, and suggested increased fragmentation of vegetation. With $79 \mathrm{~m}$ pixels, the Landsat
MSS data carried insufficient spatial resolution to confirm Schlesinger's hypothesis. General trends cited by Schlesinger et al (1990), however, including increased heterogeneity of soil resources in arid lands as they evolve into shrubby 'oases', are consistent with the discontinuous patterns of vegetation change detected around the Monument boundary and in the southern reaches of the basin, where overgrazing has been significant (Buffington and Herbel 1965). Finally, this pattern is consistent with documented evidence of windinduced mesquite dunes in this region (Gibbens et al. 1983).

\section{Conclusions}

With the increased concern about grassland replacement by woody plants, rangeland managers must consider how to 


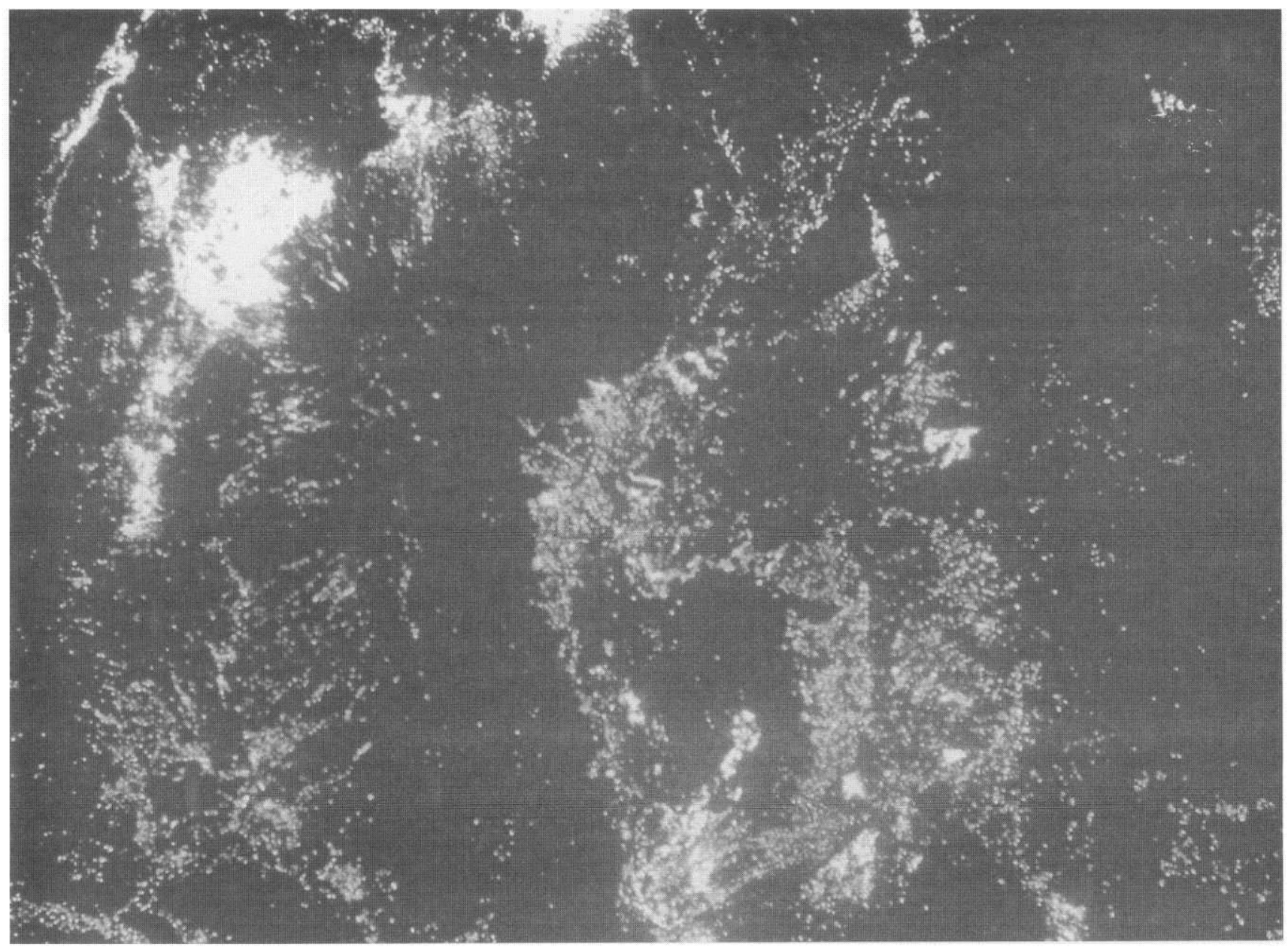

Fig. 6. $+3 \sigma$ Euclidean distance. One large swath of apparent change extends southward from the left-most lava bed.

detect and express the scales and patterns of change in rangeland ecosystems. In this study we compared methods of change detection and stratification using Landsat MSS imagery and GIS. We conclude that these methods can identify successfully the spatial patterns of extreme rangeland vegetation change and emerging risks.

Drought and heavy grazing by cattle have apparently initiated the redistribution of water, organic nitrogen, and other soil resources, causing these grasslands to change to a patchy mesquite-shrub desert. These findings underscore the inertia of change once set in, but more importantly they demonstrate we have the technology to monitor these changes. The computerassisted change-detection techniques demonstrated herein thus appear to provide managers with tools to guide future rangeland sustainability.

\section{Literature Cited}

Archer, S., C. Scifres, C.R. Bassham, and R. Maggio. 1988. Autogenic succession in subtropical savanna: conversion of grassland to thorn woodland; Ecol. Monogr. 58:111-127.

Bahre, C.J. 1991. A legacy of change: historic human impact on vegetation in the Arizona borderlands. Tucson: The Univ, of Arizona Press. 231 pages.

Buffington, L.C. and C.H. Herbel. 1965. Vegetational changes on a semi-desert grassland range from 1858 to 1963 . Ecol. Monogr. 35: 139-164.

Chavez, P.S. Jr. 1975. Atmospheric, solar, and M.T.F. corrections for ERTS digital imagery. Proc. of the Amer. Society of Photogrammetry. pp. 69-69a.

Chavez, P.S. Jr. and D.J. MacKinnon. 1994. Automatic detection of vegetation changes in the southwestern United States using remotely sensed images. Photogrammetric Eng. \& Remote Sensing. 60:571-583.
Eastman, J.R. 1992. Time series map analysis using standardized principal components. American Society of Photogrammetry and Remote Sensing/American Congress on Surveying and Mapping/RT 92 Technical Papers, Volume 1: Global Change and Education, 3-8 August, Wash., D.C., pp. 195-204

Eastman, J.R. and J.E. McKendry. 1991. Change and time series analysis. In: Explorations in Geographic Information Systems Technology (Volume 1: Change and Time Series Analysis) Geneva, Switzerland: United Nations Institute for Training and Research (UNITAR) European Office. pp. $1-56$.

Franklin, J. and D.L. Turner. 1992. The application of a geometric optical canopy reflectance model to semiarid shrub vegetation. IEEE Trans. on Geoscience and Remote Sensing. GE-30: 293-301.

Franklin, J., J. Duncan, and D.L. Turner. 1993. Reflectance of vegetation and soil in Chihuahuan Desert plant communities from ground radiometry using SPOT wavebands. Remote Sensing of Environ. 46: 291-304. 


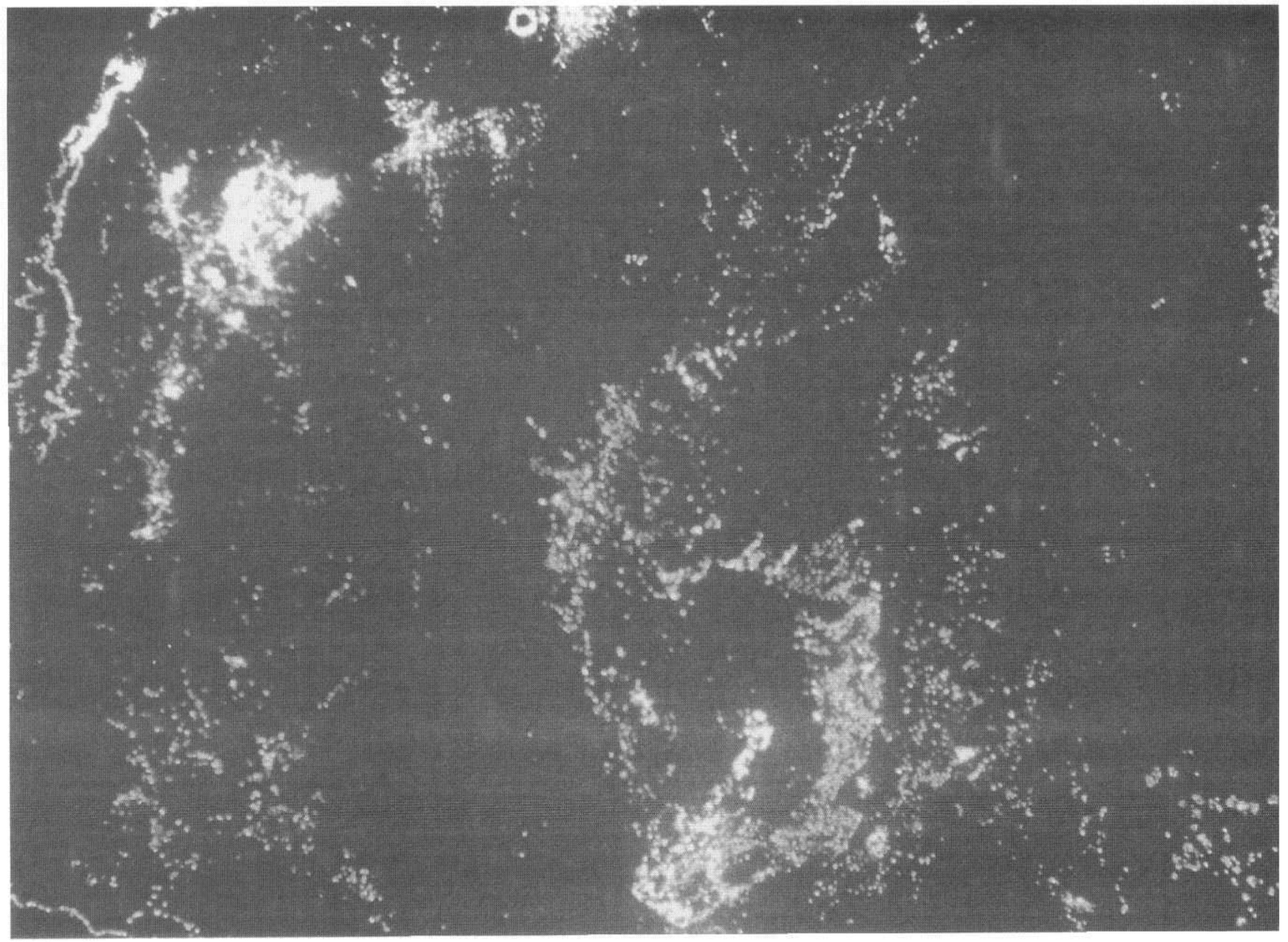

Fig. 7. +36 SPC2. The pattern of change appears more fragmented in the southernmost portion of the Jornada Basin. Areas around the White Sands National Monument also show significant vegetation change, while the Monument interior shows little or no change.

Fung, T. and E. LeDrew. 1987. Application of principal components analysis to change detection. Photogrammetric Eng. \& Remote Sensing. 53:1649-1658.

Gibbens, R.P., J.M. Tromble, J.T. Hennessy, and M. Cardenas. 1983. Soil movement in mesquite dunelands and former grasslands of southern New Mexico from 1933 to 1980 . J. Range Manage.. 36: 145-148.

Gibbens, R.P. and R.F. Beck. 1988. Changes in grass basal area and forb densities over a 64-year period on grassland types of the Jornada Experiment Range. J. Range Manage. 41:186-192.

Grover, H.D. and H.B. Musick. 1990. Shrubland encroachment in southern New Mexico, USA: an analysis of desertification processes in the American Southwest. Climatic Change. 17: 305-330.

Hennessy, J.T., R.P. Gibbens, J.M. Tromble, \& M. Cardenas. 1983. Vegetation changes from 1935 to 1980 in mesquite dunelands and former grasslands of southern New Mexico. J. Range Manage. 36:370-374.

Jensen, J.R. 1996. Introductory digital image processing: A remote sensing perspective. Englewood Cliffs, New Jersey: PrenticeHall. pp. 151-169.
Mabbutt, J.A. 1984. A new global assessment of the status and trends of desertification. Environ. Conserv. 11:103-113.

Marsh, S.E. and R.J. Lyon. 1980. Quantitative relationships of near-surface spectra to Landsat radiometric data. Remote Sensing of Environment. 10:241-261.

Photo Geographic International. 1975. Photo-Atlas of the United States. Pasadena, California: Ward Ritchie Press. p. 54

Price, J.C. 1987. Calibration of satellite radiometers and the comparison of vegetation indices. Remote Sensing of Environ. 21:15-27.

Ringrose, S. and W. Matheson. 1991. A Landsat analysis of range conditions in the Botswana Kalahari drought. Int. J. Remote Sensing. 12:1023-1051.

Ritchie, J.C., J.H. Everitt, D.E. Escobar, T.J. Jackson, and M.R. Davis. 1992. Airborne laser measurement of rangeland canopy cover and distribution. J. Range Manage, 45: 189-193.

Smith, M.O., S.L. Ustin, J.B. Adams, and A.R. Gillespie. 1990. Vegetation in deserts I: regional measure of abundance from multispectral images. Remote Sensing of Environ. 31: 1-26.
Schlesinger, W.H., J.F. Reynolds, G.L. Cunningham, L.F. Huenneke, W.M. Jarrell, R.A. Virginia, W.G. Whitford. 1990. Biological feedbacks in global desertification. Science. 247:1043-1048.

Warren, P.L., and C.F. Hutchinson. 1984. Indicators of rangeland change and their potential for remote sensing. J. of Arid Environ. 7:107-126.

West, N. 1993. Biodiversity of rangelands. J. Range Manage. 46: 2-13.

Williams, R.E., B.E. Allred, R.M. Denio, and H.A. Paulsen., Jr. 1968. Conservation, development, and use of the world's rangeland. J. Range Manage. 21: 355-360. 